\title{
Pathological Gambling after Administration of Pramipexole
}

\author{
Konstantinos Kontoangelos ${ }^{1,2 *}$, Marina Ecomomou ${ }^{1,2}$, Charalambos Papageorgiou, ${ }^{1,2}$ \\ ${ }^{1} 1^{\text {st }}$ Department of Psychiatry, Medical School, National \& Kapodistrian, University of Athens, Eginition Hospital, Athens, Greece \\ ${ }^{2}$ University Mental Health Research Institute, Athens, Greece \\ Email: *kontange@hol.gr
}

How to cite this paper: Kontoangelos, K., Ecomomou, M. and Papageorgiou, C. (2018) Pathological Gambling after Administration of Pramipexole. Case Reports in Clinical Medicine, 7, 349-351. https://doi.org/10.4236/crcm.2018.75032

Received: April 10, 2018

Accepted: May 21, 2018

Published: May 24, 2018

Copyright (c) 2018 by authors and Scientific Research Publishing Inc. This work is licensed under the Creative Commons Attribution International License (CC BY 4.0).

http://creativecommons.org/licenses/by/4.0/

(c) (i) Open Access

\begin{abstract}
Parkinson's disease is a common condition usually treated by dopaminergic agents and many behavioral abnormalities such as impulse control disorders (ICD) are connected with that usage. Pathological gambling, a form of ICD includes is a clinical condition that disrupts personal, family and occupational activity. Pramipexole a $\mathrm{D}_{2}$ AND $\mathrm{D}_{3}$ agonist may be associated with pathological gambling. We present a case of 74-year-old male patient who was diagnosed with Parkinson's disease (PD). His doctor advised him to take pramipexole $0.18 \mathrm{mg} /$ p.o./day. A month after the onset of treatment he manifested a behavior of pathological gambling. After the discontinuation of the drug all this behavior was interrupted.
\end{abstract}

\section{Keywords}

Pramipexole, Pathological Gambling, Side Effects, Parkinson Disease

\section{Introduction}

Pathological gambling (PG), hypersexuality, and compulsive shopping have been reported in association with the use of dopamine receptors agonist drugs. Parkinson's disease is a common condition, usually treated by dopaminergic agents (DA) [1]. Many behavioural abnormalities are associated with such usage, including impulse control disorders (ICDs), dopamine dysregulation syndrome and "punding". Pathological gambling, a form of ICD, comprises persistent and maladaptive gambling of various types that disrupts personal, family or occupational activity [2]. Pathological gambling may be associated with other abnormal actions such as pathological shopping, hoarding and hypersexuality. The incidence varies widely from study to study but may be up to $7 \%$ of users of dopaminergic agents. Recognition of this problem has led drug regulatory agencies to 
add precautions concerning pathological gambling to official drug information for the entire class of antiparkinsonian medications [3].

\section{Case Presentation}

This is a case of a 74-year-old male patient who was diagnosed with Parkinson's disease (PD) five years ago and he is in a mild clinical situation. His doctor advised him to take pramipexole $0.18 \mathrm{mg} /$ p.o./day. A month after the onset of treatment, the patient began to have an increased desire to visit the casino and especially slot machines. He started to increase the frequency of visits. While it is usual to go one more time a month, it gradually begins to go every day, losing in the beginning a small amount of money and then bigger. His need for sleep was reduced and progressively lost his appetite. He was feeling restless or irritable when trying to cut back or quit gambling and he was lying about the amount of time or money spends in gambling. He had a great need for gambling with increasing amount of money in order to achieve the desired excitement and he made repeated unsuccessful efforts to control gambling. He lost significant relationship and often was gambling with distressed feelings. The gambling behavior was not explained by a manic episode. After the discontinuation of the drug all this behavior was interrupted. The patient was suffering also by arterial hypertension. An informed consent form obtained from the patient to report the case.

\section{Discussion}

The prevalence of PG in prospective study of PD patients using DA has been reported between $2 \%, 3 \%$ and $8 \%$, compared to approximately $1 \%$ in the general population [4]. As in the general population, PD patients with this complication are often young, male and have psychiatric comorbidity [5]. Pathological gamblers have a deficiency in the mesolimbic dopaminergic reward system and a series of dopamine receptors has been described and the mechanism of this adverse effect due to the pramipexole action is believed to be excessive dopaminergic stimulation involving D3 receptors [6]. The $\mathrm{D}_{3}$ receptor expression is connected with the limbic areas and appears to control the phasic activity of dopaminergic neurons, which leads to the conclusion that $\mathrm{D}_{3}$ receptor has an important role in modulating the physiologic and emotional experience of novelty, reward and risk assessment and likely explains the higher rates of pathological behaviors among patients taking dopamine agonists [7] [8]. Humans that expect a monetary reward and are cured with pramipexole present a reduced interaction between the nucleus accumbens and the prefrontal cortex and probably this fact decreases the prefrontal control of impulses [9]. In the literature up to 2004, other 29 cases had been recorded. They concluded that pathological gambling needed an adjustment and modification in medication for the parkinson disease [10]. This case provides further support for the importance of screening the emergency of pathological gambling and other impulse-control dysregulation when someone is suffering from Parkinson disease. Such an approach also 
promises to help treatment selection by providing an enhanced vocabulary for discussing concepts central to the treatment of Parkinson's disease.

\section{References}

[1] Lader, M. (2008) Antiparkisonian Medication and Pathological Gambling. CNS Drugs, 22, 407-416. https://doi.org/10.2165/00023210-200822050-00004

[2] Molina, J.A., Saniz-Artiga, M.J., Fraile, A., Jiménez-Jiménez, F.J., Villanueva, C., Ortí-Pareja, M. and Bermejo, F. (2000) Pathologic Gambling in Parkinson's Disease: a Behavioral Manifestation of Pharmacologic Treatment? Movement Disorders, 15, 869-872. https://doi.org/10.1002/1531-8257(200009)15:5<869::AID-MDS1016>3.0.CO;2-I

[3] Kelley, B.J., Duker, A.P. and Chiu, P. (2012) Dopamine Agonists and Pathologic Behaviors. Parkinson's Disease, 2012, Article ID: 603631. https://doi.org/10.1155/2012/603631

[4] Avanzi, M., Baratti, M., Cabrini, S., Uber, E., Brighetti, G. and Bonfà, F. (2006) Prevalence of Pathological Gambling in Patients with Parkinson's Disease. Movement Disorders, 21, 2206-2208. https://doi.org/10.1002/mds.21072

[5] Kapogiannis, D., Mooshagian, E., Campion, P., Grafman, J., Zimmermann, T.J., Ladt, K.C. and Wassermann, E.M. (2011) Reward Processing Abnormalities in Parkinson's Disease. Movement Disorders, 26, 1451-1457. https://doi.org/10.1002/mds.23701

[6] Perachon, S., Schwartz, J.-C. and Sololoff, P. (1999) Fuctional Potencies of New Antiparkinsonian Drugs at Recombinant Human Dopamine $\mathrm{D}_{1}, \mathrm{D}_{2}$ and $\mathrm{D}_{3}$ Receptors. European Journal of Pharmacology, 366, 293-300. https://doi.org/10.1016/S0014-2999(98)00896-6

[7] Sokoloff, P., Diaz, J., Le Foll, B., Guillin, O., Leriche, L., Bezard, E., Gross, C. (2006) The Dopamine D3 Receptor: A Therapeutic Target for the Treatment of Neuropsychiatric Disorders. Current Drug Targets-CNS \& Neurological Disorders, 1, 25-43.

[8] Montastruc, L., Schmitt, L. and Bagheri, H. (2003) Pathological Gambling Behavior in a Patient with Parkinson's Disease Treated with Levodopa and Bromocriptine. Revue Neurologique, 159, 441-443.

[9] Schultz, W. (2010) Dopamine Signals for Reward Value and Risk: Basic and Recent Data. Behavioral and Brain Functions, 6, 24.

https://doi.org/10.1186/1744-9081-6-24

[10] Kurlan, R. (2004) Disambling Repetitive Behaviors in Parkinson's Disease. Movement Disorders, 19, 433-437. https://doi.org/10.1002/mds.10625 